\title{
Towards Helping Children with Attention Deficit Hyperactivity Disorder (ADHD) to Enjoy Peaceful Schooling
}

\author{
Ayoka Mopelola Olusakin, Ngozi Osarenren and Florence Obi
}

\author{
1. Department of Educational Foundations, Faculty of Education, University of Lagos, \\ Akoka-Lagos, Nigeria \\ E-mail: mopeolusakin@yahoo.com \\ 2. Counseling Psychology at the University of Lagos, Nigeria \\ 3. Special Education, University of Calabar, Calabar, Nigeria
}

KEYWORDS Helping. ADHD Children. Schooling. Enjoyment

\begin{abstract}
Children could learn better when they enjoy learning. This article seeks to direct attention to the importance of helping children with Attention Deficit Hyperactivity Disorder (ADHD) to enjoy schooling. Considering a dearth of documented Nigerian-based research in this area (only one), the U.S. Department of Education, Office of Special Education and Rehabilitative Services, Office of Special Education Programs's project report titled "Teaching Children with Attention Deficit Hyperactivity Disorder: Instructional Strategies and Practices" is condered invaluabled for all stake holders in the lives of these childern, so it is adopted as the working paper for this article. The syptoms of ADHD were pointed out while the specific ways in which teachers and parents could help these group of children were discussed. Since a child with ADHD may be able to focus when he/she is receiving frequent reinforcement, the need to work with parents and the community was emphasized.
\end{abstract}

\section{INTRODUCTION}

Enjoyment is important for children to learn with ease. Children learn to love learning when they enjoy peace in what they are doing. They enjoy the richness of their learning - not just learning different things, but learning in many different ways: indoors, out-of-doors, through play, in small groups, through art, music and sport, from each other, from adults other than teachers, before school, after school, with their parents and grandparents, formally and informally, by listening, by watching, and by doing. All these combined would help them enjoy their learning and desire to do well and also enable them to develop socially and emotionally in the cognitive, affective and psychomotor domains.

Every school should build on their own strengths to serve the needs of the children. To do this, they would need to work with parents and the whole community; they would have to think creatively about how they use the skills of everyone in the school.

It is true that children could learn better when they are excited and peacefully engaged - but

Correspondence to be addressed to:

Dr. Ayoka Mopelola Olusakin, Department of

Educational Foundations, Faculty of Education,

University of Lagos, Akoka-Lagos, Nigeria

E-mail: mopeolusakin@yahoo.com what excites and engages them best is truly excellent teaching, which challenges them and shows them what they can do. The Primary/ Elementary education system should not write off any child through low expectations. Excellent teaching gives children the life chances they deserve. And they themselves will take responsibility for making what they do. No matter the level the schools are now, with determination, they can be better.

According to the US Department of Education (2004), children with Attention Deficit Hyperactivity Disorder (ADHD) and its associated conditions frequently have problems at school including underachievement, difficulties with social skills and low self-esteem. They may experience teasing or bullying. Because ADHD children look like their peers it is not uncommon to find educators who consider the disorder an "excuse" for immature behavior rather than the neurobiological disorder it is. Without intervention, teachers and administrators may simply label the child as a troublemaker and if the condition is not properly diagnosed and managed well in the classroom, children can become isolated from their peer group, and develop other problems such as depression.

Ofovwe et al. (2006) carried out a study to establish the prevalence of ADHD among schoolaged children in Benin City, Nigeria using a total 
of one thousand, three hundred and eighty four (1384) primary school pupils, aged between six and 13 years, who were recruited from six primary schools. Teacher's ratings of the DSM-IV symptoms of ADHD were collected and analyzed as a function of gender and subtype. The results which showed that male Nigerian children who participated in the study had a higher prevalence rate support a documented trend in ADHD reports that male children have a higher rate of ADHD (Bender 1997, p. 56; Hallowell 1994, p. 18; Rief 1997, p. 12). They concluded that the results strengthen earlier observations that there is no significant geographical variation on the prevalence of ADHD if common definitions and diagnostic tools are employed. They also made the assertion that their study was the first from Nigeria and provides data for cross-cultural comparison as a prerequisite for establishing a common knowledge of ADHD. This lack of documented Nigeria-based research on ADHD makes this present work to be of great relevance to Nigerians.

\section{Symptoms of Attention Deficit Hyperactivity Disorder (ADHD)}

The major symptoms of Attention Deficit Hyperactivity Disorder (ADHD) are inattention, hyperactivity, and impulsivity.

According to the fourth edition of the Diagnostic Statistical Manual of Mental Disorders (DSM-IV) of the American Psychiatric Association (APA) (1994: 83-85), ADHD can be defined by behaviors exhibited. Individuals with ADHD exhibit combinations of the following behaviors:

Fidgeting with hands or feet or squirming in their seat (adolescents with ADHD may appear restless);

Difficulty remaining seated when such is required;

Difficulty sustaining attention and waiting for a turn in tasks, games, or group situations;

Blurting out answers to questions before the question has been completed;

Difficulty following through on instructions and in organizing tasks;

Shifting from one unfinished activity to another;

Failing to give close attention to details and avoiding careless mistakes;

Losing things necessary for tasks or activities;
Difficulty in listening to others without being distracted or interrupting;

They experience wide ranges in mood swings and having difficulty in delaying gratification.

Three subtypes of the disorder have been described in the DSM-IV and cited by Barkley (1997) These are:

(1) Predominantly inattentive type: (may not be hyperactive or impulsive) they may show a different set of behavior patterns altogether such as: Become easily distracted by any passing sight or sound; Inattentive to details; Makes lots of careless mistakes; Do not follow instructions much; Forgetful of belongings; Skips from one incomplete task to another.

(2) Predominantly hyperactive-impulsive, type: (may not be inattentive) Some behavioral symptoms exhibited by children in this condition include: Being restless or fidgety; Always squirming in their seats; Always in motion, running, climbing, even in places where they have to sit still; Answering even before the questions can be completed; Finds it difficult to wait in queues or take turns

(3) The combined types (who are inattentive, hyperactive and impulsive), they show mostly all of the symptoms discussed above at some point in time.

While other children may occasionally show some signs of these behaviors, in children with ADHD the symptoms are more frequent and more severe than in other children of the same age (US Department of Education, 2004).

In addition to having $\mathrm{ADHD}$, some children have others academic or behavioral challenges. For instance, Forness and Kavale (2001) and Schiller (1996) have documented that approximately a quarter to one-third of all children with ADHD also exhibit learning disabilities with studies finding populations where the co morbidity ranges from 7 to 92 percent (DuPaul and Stoner 1994, p. 46; Osman 2000, p. 52). Also, some children with ADHD have coexisting psychiatric disorders at a much higher rate. For example, the rate of conduct or oppositional defiant disorders varied from 43 to 93 percent and anxiety or mood disorders from 13 to 51 percent (Burt et al. 2001; Forness et al. 1998; Jensen et al. 1997; Jensen et al. 1993).

When a child exhibits behaviors associated with ADHD, consequences may include difficulties with academics and with forming cordial 
relationships with his/her peers if appropriate instructional methodologies and inter-ventions are not implemented (US Department of Education 2004).

It has been documented that there are about 1.46 to 2.46 million children with ADHD in the United States; and that these children constitute 3-5 percent of the student population (Stevens 1997) Although for years ADHD was assumed to be a childhood disorder that became visible as early as age 3 and then disappeared with the advent of adolescence, but it is now known the condition is not limited to children alone and that while the symptoms of the disorders may change as a child ages, many children with ADHD do not grow out of it (Mannuzza et al. 1998). For example, while a preschool child may show gross motor over activity by running or climbing and frequently shifting from one activity to another, older children may be restless and fidget in their seats or play with their chairs and desks. They frequently fail to finish their schoolwork, or they work carelessly. Whereas adolescents with ADHD tend to be less communicative and more withdrawn, often impulsive, reacting spontaneously without being mindful of previous plans or necessary tasks and homework.

\section{PARENTAL INVOLVEMENT}

Families that have member(s) with disabilities go through a lot of challenges. The stress of parents and siblings of the child with disabilities could at times be overwhelming. But the child is still part of the family and should be cared for. Parents have a critical role in the education of their children; this is particularly true for those with ADHD (Rey et al. 2000). Among parents of children age 6-13 years who have an emotional disturbance, 65 percent report their children also have ADHD. Parents of 28 percent of children with learning disabilities report their children also have ADHD (Wagner and Blackorby 2002, p. 7). To diagnose ADHD, parents must ascertain that the behavior exhibited by the child is inappropriate for his/her age and that the behavior has appeared early in life, before age of 7. The behavior pattern must be consistently occurring for at least six month [American Psychiatric Association (APA) 1994, p. 85]. Parents must be included as partners in planning for the student's success. Partnering with parents entails including parental input in behavioral intervention strategies, maintaining frequent communication between parents and teachers, and collaborating in monitoring the student's progress.

All children do not behave in the same manner in the same situation, it is important for the parents to know from an expert about what behavior is age appropriate for the child. Only then it is possible to diagnose ADHD as behavior inappropriate for the child of that age. Parents will need to take their children to pediatrician, psychologist or psychiatrist to diagnose whether their child's suffering from ADHD or is just immature and extra playful. Among the pediatricians, psychologists or psychiatrists, neurologists and social workers, some can prescribe medication; others may use behavioral therapies to help such children. It is necessary for the parents to know their children's problem and decide on the specialist most suited to meet their unique needs. It is important for the parent to discuss the child's problem and his/her treatment with his teacher, so that the teacher can also support the child adequately in the classroom activities.

Parents should be actively involved in making schooling enjoyable for their ADHD children.

Parents would need to help in supervising the homework of their ADHD children. This is because a child with a short attention span may have more difficulty sitting down, turning off the TV and doing homework on his own. It helps to have a specific time and place for the child to do homework. In some cases, supportive parental supervision can be valuable. This can be a positive opportunity for the parent to see what the child is doing academically. The parent can also go over concepts that the child may have missed when not paying attention.

\section{SOME TEACHING STRATEGIES FOR EFFECTING PEACEFUL LEARNING FOR CHILDREN WITH ADHD}

Teachers need to develop strategies that work with special needs children in the regular classroom. What worries some teachers most about inclusion is the fear of being unable to meet the needs of a child with a disability. Teachers need to find ways of enabling these children to learn to read and write together with their peers. Children with special needs are expected to abide by the same rules and regulations as other 
children. Too many special concessions teach children to feel different and their peers to become less tolerant.

Students should be encouraged to take responsibility for their own work and behavior. Do not make excuses or exceptions. Just one or two children with disabilities should be integrated into a mainstream primary classroom at any one time.

According to the US Department of Education (2004), teachers who are successful in educating children with ADHD use a three-pronged strategy. They begin by identifying the unique needs of the child. For example, the teacher determines how, when, and why the child is inattentive, impulsive, and hyperactive. The teacher then selects different educational practices associated with physical classroom accommodations, academic instruction and behavioral interventions, that are appropriate to meet that child's needs. Finally, the teacher combines these practices into an individualized educational program (IEP) or other individualized plan and integrates this program with educational activities provided to other children in the class.

\section{ASSESSMENT OF THE CHILD'S INDIVIDUAL NEEDS AND STRENGTHS}

The teacher in cooperation with the relevant multidisciplinary team and the child's parents should assess the unique educational needs and strengths of a child with ADHD in the class. Both academic and behavioral needs should be considered using formal diagnostic assessments and informal classroom observations. Assessments, such as learning style inventories, can be used to determine children's strengths and enable instruction to build on their existing abilities. The settings and contexts in which challenging behaviors occur should be considered in the evaluation in order to select appropriate instructional practices that will meet the academic and behavioral needs identified for the child. Select practices that fit the content, are age appropriate, and gain the attention of the child.

For children receiving special education services, integrate appropriate practices within an IEP. In consultation with other educators and parents, an IEP should be created to reflect annual goals and the special education-related services, along with supplementary aids and services necessary for attaining those goals. Plan how to integrate the educational activities provided to other children in your class with those selected for the child with ADHD (US Department of Education, (2004).

\section{THREE BASIC COMPONENTS OF SUCCESSFUL PROGRAMS FOR CHILDREN WITH ADHD}

These components according to the US Department of Education, (2004) are the physical classroom accommodations, academic instructions and behavioral interventions. The strategic integration and implementation of these three components of successful programs for children with ADHD involve the following;

\section{(1) The Physical Classroom Accommodations}

According to Rogow (1997, p. 33), it is important to emphasize that the context of the classroom is the major framework within which the teaching programs and adaptations take place. Children with ADHD often have difficulty adjusting to the structured environment of a classroom, determining what is important, and focusing on their assigned work. They are easily distracted by other children or by nearby activities in the classroom. As a result, many children with ADHD benefit from accommodations that reduce distractions in the classroom environment and help them to stay on task and learn. Certain accommodations within the physical and learning environments of the classroom can benefit children with ADHD. The furniture to be used by children with ADHD need to be the right size; if they are not, the child will be more inclined to squirm and fidget. A general rule is that a child should be able to put his or her elbows on the surface of the desk and have his or her chin fit comfortably in the palm of the hand.

Special Classroom Seating Arrangements for ADHD Students: One of the most common accommodations that can be made to the physical environment of the classroom involves determining where a child with ADHD will sit. Assign the child a seat near the teacher's desk or the front of the classroom. This seating assignment provides opportunities for monitoring and reinforcement of the child's on-task behavior.

An ADHD student could also be asked to sit near a student role model. This seat arrangement provides opportunity for children to work cooperatively and to learn from their peers in the class. 
As space permits, teachers should make available a quiet, distraction-free room or area for quiet study time and test taking. Students should be directed to this room or area privately and discreetly in order to avoid the appearance of punishment.

Instructional Tools and the Physical Learning Environment: Teachers need to make use of special instructional tools to modify the classroom learning environment and accommo-date the special needs of their students with ADHD. They also need to monitor the physical environment, keeping in mind the needs of these children.

Teach the child to use a pointer to help visually track written words on a page. For example, provide the child with a bookmark to help him/her follow along when students are taking turns reading aloud.

Set a timer to indicate to children how much time remains in the lesson and place the timer at the front of the classroom; the children can check the timer to see how much time remains. Interim prompts can be used as well. Tell the children the time at which the lesson is starting and the time at which it will conclude (US Department of Education (2004).

At certain times, the teacher can make use of music on a tape recorder to prompt children that they are too noisy.

\section{(2) Academic Instruction in Helping a Child with ADHD}

Children with ADHD learn best with a carefully structured academic lesson-one where the teacher explains what he/she wants children to learn in the current lesson and places these skills and knowledge in the context of previous lessons. Effective teachers preview their expectations about what students will learn and how they should behave during the lesson. Prepare students for the day's lesson by quickly summarizing the order of various activities planned. Also review the previous lessons on each topic. For example, remind children that yesterday's lesson focused on learning how to write a story. Make sure they have learnt the previous topic before describing the current lesson.

State what students are expected to learn during the lesson. For example, explain to students that a language arts lesson will involve reading a story and identifying new vocabulary words in the story.
Describe how students are expected to behave during the lesson. For example, tell children that they may talk quietly to their neighbors as they do their seatwork or they may raise their hands to get your attention. The simpler the expectations communicated to an ADHD student, the more likely it is that he or she will comprehend and complete them in a timely and productive manner. Let the students know how to obtain help in mastering the lesson. For example, refer children to a particular page in the textbook for guidance on completing a worksheet.

Structure and consistency are very important for children with ADHD; because many of them might not cope well with change. Minimal rules and alternatives could be better for these children and need to understand clearly what is expected of them, as well as the consequences for not adhering to expectations.

Encourage the students' participation in the classroom by providing them with private, discreet cues to stay on task and advance warning that they will be called upon shortly. Avoid bringing attention to differences between ADHD students and their classmates and avoid the use of sarcasm and criticism.

Use a variety of audiovisual materials to present academic lessons and ask question from individual students to assess their mastery of the lesson. You can ask students to demonstrate how they arrived at the answer to a problem, or you can ask individual students to state, in their own words, how the main character felt at the end of the story. Ask for the correct answer after allowing a child sufficient time to work out the answer to a question. Ask follow-up questions that give children an opportunity to demonstrate what they know (US Department of Education 2004).

To identify students who need additional assistance, watch for signs of lack of comprehension, such as daydreaming or visual or verbal indications of frustration. Then provide these children with extra explanations, or ask another student to serve as a peer tutor for the lesson.

Help students correct their own mistakes by describing how students can identify and correct their own mistakes. Help students to be focused and to keep working on their assigned task. For example, you can provide follow-up directions or assign learning partners. These practices can be directed at individual children or at the entire class.

Teachers of children with ADHD also need to guide them with follow-up directions. 
After giving directions to the class as a whole, provide additional oral directions for a child with ADHD. For example, ask the child if he/she understood the directions and repeat the directions if need be. Follow-up directions could be provided in writing. For example, write the page number for an assignment on the chalkboard and remind the child to look at the chalkboard if he/she forgets the assignment.

Break down assignments into smaller, less complex tasks and highlight key words in the instructions on worksheets to help the child with ADHD focus on the directions. Prepare the worksheet before the lesson begins, or underline key words as you and the child read the directions together.

The aims of literacy instruction apply to all children because children with ADHD are more like their peers than they are different from them. When reading, show children how to identify and highlight a key sentence, or have them write it on a separate piece of paper, before asking for a summary. Monitor the noise level in the classroom, and provide corrective feedback, as needed. If the noise level exceeds the level appropriate for the type of lesson, remind all students-or individual students-about the behavioral rules stated at the beginning of the lesson.

Effective teachers conclude their lessons by providing advance warning that the lesson is about to end, checking the completed assignments of at least some of the students with ADHD, and instructing students how to begin preparing for the next activity.

Provide advance warning that a lesson is about to end like 5 or 10 minutes before the end of the lesson (particularly for seatwork and group projects) how much time remains. You may also want to tell students at the beginning of the lesson how much time they will have to complete it.

Check completed assignments for at least some students. Review what they have learned during the lesson to get a sense of how ready the class was for the lesson and how to plan the next lesson.

Instruct students on how to begin preparing for the next lesson. For example, inform children that they need to put away their textbooks and come to the front of the room for a large-group spelling lesson.

Language Arts and Reading Comprehension: To help children with ADHD who are could not read well improve their reading comprehension skills, the teacher can:
(1) Establish a fixed time each day for silent reading as postulated by Manzo and Zehr (1998) and Holt and O'Tuel (1989).

(2) Ask the child to read a story silently while listening to other students or the teacher read the story aloud to the entire class.

(3) Pair the child with ADHD with another student partner who is a strong reader. The partners take turns reading orally and listening to each other.

(4) Ask the child to make storyboards that illustrate the sequence of main events in a story.

(5) Schedule storytelling sessions where the child can retell a story that he or she has read recently.

(6) Schedule play acting sessions where the child can role-play different characters in a favorite story.

(7) Keep a word bank of new or "hard-to-read" sight-vocabulary words.

(8) Play board games that provide practice with target reading-comprehension skills or sightvocabulary words.

(9) Set apart specific computer time for the child to have drill-and-practice with sight vocabulary words.

(10) Make available to students a second set of books and materials that they can use at home.

(11) Allow and encourage students to use published book summaries, synopses, and digests of major reading assignments to review reading assignments.

Using Assistive Technology to Teach Phonics: All students with or without ADHD, can benefit from the use of technology (such as computers and projector screens), which makes instruction more visual and allows students to participate actively. Computer-based educational software can help children learn academic subjects. Computer-based educational software can help children learn academic subjects. The best programs provide immediate feedback and appealing, changing visual and auditory input. Many feature cartoon characters that function like an encouraging tutor. The newer educational software allows the teacher to customize the program by changing the difficulty deleting voices, and changing the reward frequency. In other cases, educational specialists may use software designed to remediate a specific problem.

The use of a word processor or a voice recog- 
nition program can help individuals who have difficulty with getting their thoughts out on paper. There are a number of excellent typing and word processing programs for children.

Software programs are available that focus on the development or strengthening of specific skills used in reading, including phonics, decoding words, sounding out words, parts of speech and spelling.

A computer can be used to provide opportunities for students to drill and practice with phonics and grammar lessons. Computers can be used to promote successful and more efficient reading experiences for students by offering alternative strategies. Technology is seen as an integral support in these programs.

Some early software programs work on preand early reading language skills which focus on letter identification, word patterns, rhyming and early sound to letter associations. Children learn best when words are used within a context.

Other software programs focus on the development and assessment of reading skills at different grade levels. Reading activities include recognizing, building and comprehending hundreds of new words used in context. These programs are good for reading practice and portfolio assessment

Series of activities for elementary students designed to teach phonological awareness skills through an interactive educational game format. Software features and programs that enhance independent reading opportunities can make the computer a "virtual reading machine." Using textto-speech technology enriches learning by having the computer highlight text and read it aloud as the student follows along

Talking word processors (TWP) are writing software programs that provide speech feedback as the student writes, echoing each letter as it is typed and each word as the spacebar is pressed. Many of these inexpensive programs typically used to assist with writing, also incorporate powerful tools for reading. Students with learning disabilities find that having written material read aloud assists them to better edit, comprehend and organize. Once any file (story from a book, assignment, article, typed information, etc.) is imported into a talking word processor, the text can be read aloud to the student. These TWP programs offer other adjustments such as enlarging the size of the text and changing the color of the foreground, background and highlighting box to assist students in following along as the text is read. Text Readers are software programs that read all the text in any given document or application and often include other assistive features such as word prediction and spell check. Those with a reading disability, but with adequate vision most often use them to for example;

Read and Write: This easy to use floating tool bar works with any Windows software program such as a word processor, spreadsheet, database, and email or internet options. It has five areas of support: speech feedback, screen reading, phonetic spell checker, word Text Assist is an easy-to-use application that converts text into speech. You can use it to read e-mail messages and text documents, and even with Internet chat rooms. Simply highlight text and let it go to work. It is fully customizable, offering several different voices that could be modified in pitch, volume, and speed.

Lexia's phonics-based interactive reading programs are designed to facilitate the acquisition of decoding skills. With the easy-to-use writing with Symbols word processing program, students who cannot read can follow the pictures that accompany any reading passage. This reading assistance program shows symbols of words above the actual written text and also speaks the picture/words out loud.

TextAloud is a floating toolbar that lets you listen to text that you copy to the clipboard. When you highlight and copy text, the program begins to read it back to you. You can read any email message, text file or web page or save it to listen to later; it allows unlimited sizes so copy an entire eBook and save it as a file. The program uses Microsoft text-to-speech capabilities.

Apart from using the computer, to help children with ADHD master rules of phonics, teach the child mnemonics that provides reminders about hard-to-learn phonics rules (Scruggs and Mastropieri 2000). Also teach the child to recognize and read word families that illustrate particular phonetic concepts.

Have Writing Skills: Balanced literacy programs look to integrate writing and reading activities in elementary classrooms. Thematic units provide the content for both guided and independent activities for learning.

But, some software programs and internet sites contain over-stimulating graphic violent or sexual themes. Teachers must supervise/monitor 
the internet use of the children. Children with ADHD may be more vulnerable to the adverse effects of over-stimulation

Teach the child classroom standards for acceptable written work, such as format and style.

Teach the student how to describe the major parts of a story by making use of a storyboard with parts listed for this purpose.

Provide the child with a list of items to check when proofreading his/her own work.

To help children with ADHD who are poor in spelling, make use of everyday events to teach difficult spelling words in context. Assign spelling words that the child routinely uses in his/her speech each day.

Ask the child to keep a personal dictionary of frequently misspelled words.

You can use index cards of frequently misspelled words sorted alphabetically (US Department of Education).

Provide the child that has difficulty with writing with a special opportunity such as a separate table, to complete his/her handwriting assignments. Also teach the child to use his/her finger to measure how much space to leave between each word in a written assignment. Ask the child to use special paper with vertical lines to learn to space letters and words on a page. You can also teach handwriting skills through a structured program (Olsen 2003).

Basic Skills in Mathematics: In teaching Mathematics, show children how to underline the important facts and operations.

Numerous individualized instructional practices can help children with ADHD improve their basic computation skills such as: Teaching the student to recognize patterns when adding, subtracting, multiplying, or dividing whole numbers.

Pair up a child with ADHD with another student and provide opportunities for the partners to quiz each other about basic computation skills.

Teach the child to master the basic (not complicated) mathematical symbols. If children do not understand the symbols used in math, they will not be able to do the work. Teach the child with real-life opportunities to practice target money skills. For example, ask the child to calculate his or her change when paying for lunch in the school cafeteria, or set up a class store where children can practice calculating change. Color code basic arithmetic symbols, such as + , ,$- \div, \times$, and $=$, to provide visual cues for children when they are computing whole numbers.
Teach the child to play board games to practice adding, subtracting, multiplying, and dividing whole numbers.

Guide students to perform a quick drill every day to practice basic computation of Mathematics and have them track their own performance.

To help children with ADHD improve their skill in solving word problems in Mathematics, teach the child to read a word problem two or more times before beginning to compute the answer. Also teach the child clue words that identify which operation to use when solving word problems. Teach students to ask guiding questions in solving word problems.

Ask the student to create and solve word problems that provide practice with specific operations, such as addition, subtraction, multiplication, or division. These problems can be based on recent, real-life events in the child's life.

Some children with ADHD benefit from using special materials to help them complete their Mathematics assignments, such as:

Making use of number lines for the child to use when computing whole numbers and ask the child to use graph paper to help organize columns when adding, subtracting, multiplying, or dividing whole numbers. Allow the student to use a calculator to check computations made in answering assigned word problems (US Department of Education).

Power tests may not allow children with ADHD to demonstrate what they truly know due to their potential preoccupation with time limitation. Allow students with ADHD more time to complete quizzes and tests in order to eliminate test anxiety, and provide them with other opportunities, methods, or test formats to demonstrate their knowledge.

\section{(3) Effective Behavioral Interventions}

The third major component of effective instruction for children with ADHD involves the use of behavioral interventions. Children with ADHD often act immaturely and have difficulty learning how to control their impulsiveness and hyperactivity. They may have problems forming friendships with other children in the class and may have difficulty thinking through the social consequences of their actions.

The purpose of behavioral interventions is to assist students in displaying the behaviors that 
are most conducive to their own learning and that of classmates. Well-managed classrooms prevent many disciplinary problems and provide an environment that is most favorable for learning. When a teacher's time must be spent interacting with students, whose behaviors are not focused on the lesson being presented, less time is available for assisting other students. Behavioral interventions should be viewed as an opportunity for teaching in the most effective and efficient manner, rather than as an opportunity for punishment.

Behavioral contracts and management plans would be needed to identify specific academic or behavioral goals for the child with ADHD, along with behavior that needs to change and strategies for responding to inappropriate behavior. Work with the child to cooperatively identify appropriate goals, such as managing the time effectively and studying well. Take the time to ensure that the child agrees that his/her goals are important to master. Behavioral contracts and management plans are typically used with individual children, as opposed to entire classes, and should be prepared with input from parents. For example; to assist the student with ADHD who often have difficulty finishing their assignments on time and are easily distracted with time management, the teacher need to:

- Help him/her to improve his/her organization of homework and other daily assignments in order to save time.

- Teach the child to use color-coded folders to help organize assignments for different academic subjects

- Assign the child a partner to help record homework and other seatwork in the assignment notebook and file work sheets and other papers in the proper folders. Also ask the child to periodically sort through and clean out his/her desk, book bag, and other special places where written assignments are stored.

- Teach the child how to read and use a clock or wristwatch to manage time when completing assigned work. Also teach the child how to read and use a calendar to schedule assignments. Provide the child with supervised opportunities to break down a long assignment into a sequence of short, interrelated activities (US Department of Education 2004).

And for a child with ADHD often has difficulty in learning how to study effectively on his/her own, the teacher should;
- Regularly review the student's progress through progress reports submitted by other teachers and will act as the liaison between home and school.

- Permit the student to meet with this advisor on a regular basis to plan and organize for the week and to review progress and problems from the past week.

- Make sure the child has an assignment notebook to help organize homework and other class work.

- Also teach a child how to adapt instructional worksheets. For example, the child can use a blank piece of paper to cover the other questions on the page.

- Teach a child with ADHD how to take notes when organizing key academic concepts that he/she has been taught (Archer and Gleason 2002, p. 31).

- Provide the child with a checklist of mistakes that he/she frequently makes in written assignments in any of the academic subjects.

- Teach the child how to use this list when proofreading his/her work at home and school and provide the child with a checklist that identifies categories of items needed for homework.

- Keep track of how well your students with ADHD complete their assignment.

- Discuss and resolve with them and their parents any problems in completing these assignments.

Making Use of Rewards to Reinforce Appropriate Behavior: There should be immediate reward for appropriate behavior so as to positively reinforce it. These rewards can include stickers, such as school emblems, or privileges, such as extra time on the computer play station. Children should be involved in the selection of the reward. If children are invested in the reward, they are more likely to work for it.

Use token economy systems to motivate a child to achieve a goal identified in a behavioral contract (Barkley 1990). For example, a child can earn points for each homework assignment completed on time. In some cases, students also lose points for each homework assignment not completed on time. After earning a specified number of points, the student receives a tangible reward, such as extra time on a computer. Token economy systems are often used for entire classrooms, as opposed to solely for individual students. 
Positive verbal reinforcement is also an important and effective way of strengthening appropriate behavior. The most common form of positive verbal reinforcement is praise given to a student when he or she begins and completes an activity or exhibits a particular desired behavior. Simple phrases such as "good girl" or "good boy" could encourage a child to act appropriately. Praise should be given for the specific positive behavior displayed by the student. The comments should focus on what the student did right and should include exactly what part(s) of the student's behavior was desirable. Rather than praising a student for not disturbing the class, for example, a teacher should praise him/her for quietly completing a Mathematics assignment on time.

Give praise immediately because the sooner that approval is given regarding appropriate behavior, the more likely the student will repeat it.

The comments used by teachers to praise appropriate behavior should vary; when students hear the same praise statement repeated over and over, it may lose its value.

Appropriate behavior should receive consistent praise. Consistency among teachers with respect to desired behavior is important in order to avoid confusion on the part of students with ADHD. Similarly, students will notice when teachers give insincere praise, and this insincerity will make praise less effective.

Teachers need to focus their behavioral intervention strategies on praise rather than on punishment. Negative consequences may temporarily change behavior, but they rarely change attitudes and may actually increase the frequency and intensity of inappropriate behavior by rewarding misbehaving students with attention. Moreover, punishment may only teach children what not to do; it does not provide children with the skills that they need to do what is expected. Positive reinforcement produces the changes in attitudes that will shape a student's behavior over the long term.

In addition to verbal reinforcement, it could sometimes be helpful for teachers to selectively ignore inappropriate behavior. This technique is particularly useful when the behavior is unintentional or is intended solely to gain the attention of teachers or classmates without disrupting the classroom or interfering with the learning of others.

Remove unnecessary items. Teachers often find that certain objects) distract the attention of students with ADHD in the classroom. The removal of such items is generally most effective after the student has been given the choice of putting it away immediately and then fails to do so.

Provide calming play-stations. While some objects can be distracting for both the students with ADHD and peers in the classroom, some children with ADHD can benefit from having access to objects that can be manipulated quietly. Play-stations may help children gain some needed sensory input while still attending to the lesson.

Permitting students with ADHD to leave class for a moment, perhaps on an errand (such as returning a book to the library), can be an effective means of settling them down and allowing them to return to the room ready to concentrate.

Students receive activity reinforcement when they are encouraged to perform a less desirable behavior before a preferred one.

Functional behavioral assessment which is a systematic process for describing problem behavior and identifying the environmental factors and surrounding events associated with problem behavior could be employed. This involves the team that works closely with the child exhibiting problem behavior (1) observing the behavior and identifies and defines its problematic characteristics, (2) identifying which actions or events precede and follow the behavior, and (3) determining how often the behavior occurs. The results should be used to develop an effective and efficient intervention and support plan (US Department of Education 2004).

Students should be trained to monitor and evaluate their own behavior without constant feedback from the teacher. In a typical selfmanagement system, the teacher identifies behaviors that will be managed by a student and provides a written rating scale that includes the performance criteria for each rating. The teacher and student separately rate student behavior during an activity and compare ratings. The student earns points if the ratings match or are within one point and receives no points if ratings are more than one point apart; points are exchanged for privileges. With time, the teacher involvement is removed, and the student becomes responsible for self-monitoring (DuPaul and Stoner as cited in Shinn et al. 2002).

Teachers could also use behavioral prompts with their students. These prompts help remind 
students about expectations for their learning and behavior in the classroom. For example, teachers can establish simple, non-intrusive visual cues to remind the child to remain on task. For example, you can point at the child while looking him/her in the eye, or you can hold out your hand, palm down, near the child.

When talking to a child, you could move to where the child is standing or sitting. Your physical proximity to the child would help the child to focus and pay attention to what you are saying.

Use hand signals to communicate privately with a child with ADHD. For example, ask the child to raise his/her hand every time you ask a question. A closed fist can signal that the child knows the answer; an open palm can signal that he/she does not know the answer. You would call on the child to answer only when he/she makes a fist.

In some instances, children with ADHD benefit from instruction designed to help students learn how to manage their own behavior.

\section{PEERMEDIATION}

Enabling the child to join peers helps him/her to learn more, and the more the child learns, the better interactions with peers will be. Encourage students to work together in small groups to maximize their own and the other partner's learning. Use strategies such as Think-Pair-Share where teachers ask students to think about a topic, pair with a partner to discuss it, and share ideas with the class (Slavin 2002, p. 78).

At times, teachers may adapt strategies to suit specific children, but they should not treat children with ADHD much differently than they treat their other students. Helping children with ADHD know that they are more like peers than unlike them will enable those with ADHD to achieve more. Giving special privileges to children with ADHD could impede their progress toward learning and acceptance (Rogow 1997, p. 45).

Peers without ADHD could learn from children with ADHD even as the children with ADHD are learning from them, therefore inclusion could be of great benefits to all children.

Members of a student's peer group can positively impact the behavior of students with ADHD. Many schools now have formalized peer mediation programs, in which students receive training in order to manage disputes involving their classmates. One of the most important skills taught both at home and school is how to get along with others. This may be the most important skill the ADHD child has to learn. Some ADHD individuals are naturally gregarious and popular. However, there are also a large number of individuals who have significant social deficits. Teach children with ADHD appropriate social skills using a structured class. For example, you can ask the children to role-play and model different solutions to common social problems. Problem Solving Sessions are useful in discussing how to resolve social conflicts. Conduct impromptu discussions with each of the students or with a small group of students where the conflict arises. In this setting, ask two children who are arguing about a game to discuss how to settle their differences. Encourage the children to resolve their problem by talking to each other in a supervised setting (US Department of Education).

It is important to provide for the generalization of these skills, including structured opportunities for the children to use the social skills that they learn. Offering such classes, or experiences, to the general school population can positively affect the school climate.

\section{MEDICATION}

The number of children taking psychotropic medication has increased substantially in recent years. That increase is consistent with the rising number of children diagnosed with ADHD. Psychotropic medications treat a variety of behavior, emotional, and mental disorders, including ADHD. Most children treated with medication for ADHD are prescribed stimulant medication, such as methylphenidate/Ritalin. When used, the stimulant helps a child who has ADHD focus and reduces the child's excess fidgeting and hyperactivity. Medication alone doesn't solve a child's behavioral problems, he argues, and therapy and changes in discipline at school and at home sometimes can be enough in themselves (Diller 1998, p. 55).

According to Diller (2002, p. 14), the increase in the number of prescriptions doctors write for treating ADHD is staggering and the number of prescriptions written for methylphenidate has increased by a factor of five since 1991. About 80 percent of the 11 million prescriptions doctors write for that medication each year treat childhood ADHD. In addition, production of Adderall and 
Dexedrine, also used to treat ADHD, has risen 2,000 percent in nine years.

Although Diller (1998, p. 67) prescribes stimulant medication for children with ADHD, he questions the large number of children currently on the medication in the United States.

Increased Drug Use for Kids of Almost All Ages: The use of stimulant medication is not seen just in school-aged children. The number of preschool children using stimulant medication for ADHD has increased significantly as well. A study, Trends in the Prescribing of Psychotropic Medications to Preschoolers, published in the Journal of the American Medical Association last February, found that psychotropic medication use tripled in preschool children ages two to four over a five-year span (Diller 2002, p. 128).

\section{CONCLUSIONS}

For effective teaching in agreement with the U.S. Department of Education Office of Special Education and Rehabilitative Services, Office of Special Education Programs, report 2004, the three main components of a successful strategy for educating children with ADHD are classroom accommodations, academic instruction, and behavioral interventions. By incorporating techniques from these three areas into their everyday instructional and classroom management practices, teachers will be empowered to improve both the academic performance and the behavior of their students with ADHD. In doing so, teachers will create an enhanced learning environment. These techniques are not just useful in helping children with ADHD, but they are as well relevant in helping other children.

The academic success of a child is often dependent on his/her ability to attend to tasks, to the teacher and classroom expectations with minimal distraction. Such skill enables a student to acquire necessary information, participate in classroom activities/discussions and complete assignments (Forness and Kavale 2001).

Parents, siblings, extended family and community support could be quite helpful in helping the children with ADHD to enjoy peaceful schooling.

Community support is important during and after the time of the initial diagnosis. It is easy for a family to become overworked or overwhelmed. At such a point, the family might be tempted to withdraw into itself just when support is most needed. Extended family can be an important source of support, but can sometimes also be a source of tension. Parents could feel that extended family members do not understand the situation.

Parents should be aware that some children may need medication adjustment so that they can focus enough to do their homework. For some students, particularly those with learning disabilities, the standard amount of homework is just too much. Parents could ask for extra assignments so that the student can work at home on assignments not finished during the day. Teachers can offer encouragement, support, and assistance to prevent students from becoming frustrated with an assignment. This help can take many forms, from enlisting a peer for support to supplying additional materials or information. Parents and teachers can sometimes use easily available commercial software for academic remediation and for enrichment.

All these put together would help the Nigerian children (those with ADHD and others) to enjoy peaceful learning.

\section{REFERENCES}

American Psychiatric Association 1994. Diagnostic and Statistical Manual Of Mental Disorders, 4th Ed. Washington, DC: American Psychiatric Association. Archer A, Gleason M 2002. Skills for School Success: Book 5. North Billerica, MA: Curriculum Associates, Inc.

Barkley RA 1990. Attention Deficit Hyperactivity Disorder: A Handbook For Diagnosis and Treatment. New York: Guilford.

Barkley RA 1997. Behavioral inhibition, sustained attention, and executive functions: Constructing a unifying theory of ADHD. Psychological Bulletin, 121(1): 65-94.

Bender W 1997. Understanding ADHD: A Practical Guide for Teachers and Parents. Upper Saddle River, NJ: Merrill/Prentice Hall.

Burt SA, Krueger RF, McGue M, Iacono WG 2001. Sources of Co variation among Attention-Deficit/Hyperactivity Disorder, Oppositional Defiant Disorder, and Conduct Disorder: The Importance of Shared Environment. Journal of Abnormal Psychology, 110: 516-525.

Diller LH 1998. Running on Ritalin: A Physician Reflects on Children, Society and Performance in a Pill. New York: Bantam Books,

Diller LH 2002. Should I Medicate my Child? Sane Solutions for Troubled Kids with and Without Psychiatric Drugs. New York: Basic Books.

DuPaul GJ, Stoner G 1994. ADHD in the Schools: Assessment and Intervention Strategies. New York: Guilford Press.

DuPaul GJ, Stoner G 2002. Interventions for Attention Problems. In: MR Shinn, HM Walker, G Stoner (Eds.): Interventions for Academic and Behavior 
Problems II: Preventive and Remedial Approaches. Bethesda, MD: National Association of School Psychologists, pp. 913-938.

Forness SR, Kavale KA 2001. ADHD and a Return to the Medical Model of Special Education. Education and Treatment of Children, 24(3): 224-247.

Forness SR, Kavale KA, San Miguel S 1998. The Psychiatric Co morbidity Hypothesis Revisited. Learning Disability Quarterly, 21: 203-207.

Hallowell E 1994. Driven to Distraction: Recognizing and Coping with Attention Deficit Disorder from Childhood Through Adulthood. Tappan, NJ: Simon and Schuster.

Holt SB, O'Tuel FS 1989. The Effect of Sustained Silent Reading and Writing on Achievement and Attitudes of Seventh and Eighth Grade Students Reading Two Years Below Grade Level. Reading Improvement, 26: 290-297.

Jensen PS, Martin D, Cantwell DP 1997. Co morbidity in ADHD: Implications for Research, Practice, and DSM-IV. Journal of the American Academy of Child and Adolescent Psychiatry, 36: 1065-1079.

Jensen PS, Shertvette RR, Zenakis SN, Ritchters J 1993. Anxiety and Depressive disorders in attention deficit disorder with hyperactivity: New findings. American Journal of Psychiatry, 150: 1203-1209.

Mannuzza S, Klein RG, Bessler A, Malloy P, LaPadula M 1998. Adult Psychiatric Status of Hyperactive Boys as Grown Up. American Journal of Psychiatry, 155: 493-498.

Manzo KK, Zehr MA 1998. Take note. Education Week, 18(3): 3 .

Ofovwe CE, Ofovwe GE, Meyer A 2006. The Prevalence of Attention-Deficit/Hyperactivity Disorder Among School Aged Children in Benin City, Nigeria. Journal of Child and Adolescent Mental Health, 18(1): 1-5

Olsen J 2003. Handwriting Without Tears. Retrieved September 15, 2005, from http://www.hwtears.com

Osman BB 2000. Learning Disabilities and The Risk of Psychiatric Disorders in Children and Adolescents.
In: L Greenhill (Ed.): Learning Disabilities In Children With a Psychiatric Disorder. Washington, DC: American Psychiatric Association, pp. 33-57.

Rey JM, Walter G, Plapp JM, Denstire E. 2000. Family Environment in Attention Deficit Hyperactivity, Oppositional Defiant and Conduct Disorders. Journal of Psychiatry, 34: 453-445

Rief SF 1997. The ADD/ADHD Checklist: An Easy Reference for Parents and Teachers. Reston, VA: Council for Exceptional Children.

Robelia B 1997. Tips for Working With ADHD Students of All Ages. Journal of Experimental Education, 20(1): 51-53

Rogow SM 1997. Language, Literacy and Children With Special Needs, Ontario, Canada, The Pippin Teachers Library, Pippin Publishing: Scarborough

Schiller E 1996. Educating Children With Attention Deficit Disorder. Our Children, 22, no.2: 32-33.

Scruggs TE, Mastropieri MA 2000. The effectiveness of mnemonic instruction for students with learning and behavior problems: An update and research synthesis. Journal of Behavioral Education, 10, nos. 2-3: $163-$ 173.

Slavin RE 2002. Education Psychology: Theory into Practice. Boston, MA: Allyn and Bacon.

Stevens SH 1997. Classroom Success for The LD and ADHD Child. Winston-Salem, NC: John F. Blair.

Todd, A. W., R. H. Horner, G. Sugai and J. R. Sprague. 1999. Effective Behavior Support: Strengthening School-Wide Systems Through a Team-Based Approach. Effective School Practices, 17(4): 23-37.

U.S Department of Education Office of Special Education and Rehabilitative Services, Office of Special Education Programs, 2004. Teaching Children With Attention Deficit Hyperactivity Disorder: Instructional Strategies and Practices, Washington, D.C.

Wagner M, Blackorby J 2002. Disability Profiles of Elementary and Middle School Students with Disabilities. Menlo Park, CA: SRI International. 